may be deep narrow channels with a rising gradient at both ends. Several of these channels are known in East Anglia; one seems to commence a few miles south of Cambridge, and follows approximately the line of the L.N.E.R. to Bishop's Stortford at least as far as Newport. It deepens rapidly southward, and if it is a normal river channel it must somewhere enter the sea, possibly following the Lea valley into the Thames estuary. If so, it might cause grave difficulty to engineering projects (as other such channels have done elsewhere), like that for a Thames tunnel east of the Lea valley. The buried channel of the Thames higher up is well known, but if the Newport channel does indeed enter the Thames estuary, its depth below sea-level would far exceed that of the known channel. It would therefore be of great interest both to geologists and engineers if such channels could be detected with certainty by geophysical methods.

The lecture briefly describes such applied geophysical methods, after discussing the scope of geophysics and the history and present position of the main 'pure' problems of geophysics. It should be added that the term geophysics is used in the lecture in a restricted sense : and such a remark as "geophysicists in this country do not concern themselves very much with the electric and magnetic field of the earth, which are observed in detail in various observatories", and the mention of the Carnegie Institution's Geophysical Laboratory without reference to the same Institution's great Department of Terrestrial Magnetism, must be interpreted as betokening unfamiliarity born of lack of personal interest in these further fields of geophysics.

\section{History of Bitumen}

$\mathrm{T}$ O-DAY, when petroleum with its vast range of derivatives is regarded as indispensable to the welfare of man, it is wholesome to be reminded of the salient factors which gradually extended its usefulness during the course of some five thousand years. It is equally salutary to have delineated handicaps of lack of knowledge, apparatus and facilities, which nevertheless were minimised by the ingenuity of ancient peoples who employed bitumen for a variety of purposes still recognised to-day.

A booklet entitled "The Story of Bitumen" (presumably by R. J. Forbes of Amsterdam, who last year contributed a similar article to the periodical Bitumen entitled "Aus der ältesten Geschichte des Bitumens") recently issued by Shell-Mex, Ltd., gives a brief account of the exploitation of bitumen from earliest records of its existence to about A.D. 1800 . Abundant deposits were known even to the most ancient civilisations inhabiting the region between the Nile valley and that of the Indus, but production was necessarily confined to surface operations by lack of knowledge of the technique of deep drilling and absence of geological information on deeper oil or rock-asphalt deposits. At the end of the period reviewed, in spite of vicissitudes which hindered rather than accelerated growth of the industry, particularly at the time of the later Roman Empire, the majority of deposits of which we now have knowledge were actually known. Then, however, the importance of petroleurn was negligible compared with present-day values, for the internal combustion engine which was later to give such tremendous impetus to the industry and create such a wide- spread demand for petroleum products was not yet discovered.

Records of actual production in ancient times are naturally scanty. It is obvious, however, that methods were extremely crude, as it is authentically reported that bitumen was recovered from the Dead Sea by men in rafts who simply 'hacked off' as large a piece of the floating mass as they could conveniently carry away. Similarly, until the eleventh century, only the most primitive attempts towards distillation were made : and this fact virtually excluded the use of light combustible oils. Gradually, however, more elaborate and practical methods were evolved, until at the beginning of the nineteenth century it may safely be said that the foundations of modern distillation technique were laid. Even so, no appreciable growth of the industry took place until after 1860, when deep drilling came within the realms of possibility. It is surprising, therefore, that in spite of all these handicaps and difficulties to easy production, we find bitumen was used extensively in antiquity as a building and road material, as a waterproofing agent and in various guises as a weapon in times of warfare. In comparatively recent times it was universally used also for lighting and heating purposes and as an ingredient of paints.

The booklet, in addition to tracing the story of bitumen, gives a chronological list of outstanding dates in the history of bitumen and includes a bibliography on petroleum and bituminous materials which, together with the numerous excerpts from early works quoted in the text, should provide a useful background to a historical study of the petroleum industry.

\section{University and Educational Intelligence}

BELFAST.-Dr. H. Barcroft, lecturer in physiology at University College, London, has been appointed to the Dunville chair of physiology in succession to Prof. T. H. Milroy, who is retiring on October 1. Dr. D. C. Harrison, lecturer in biochemistry in the University of Sheffield, has been appointed to the J. C. White chair of biochemistry, in succession to the late Prof. J. H. Milroy.

Colonel S. H. Browne, formerly of the Indian Medical Service, has bequeathed to the University $£ 10,000$ to found medical research scholarships.

Cambridge.-The Royal College of Veterinary Surgeons has intimated to the Vice-Chancellor that candidates who submit evidence that they are graduates in the Natural Sciences Tripos and that in the course of their examination they have passed in physiology, pathology, biochemistry and anatomy, may be exempted from the second examination conditionally on their passing the prescribed examination in animal management before the third examination.

At St. John's College, F. J. S. Hollick has been elected into a fellowship.

OxFond.-The Halley Lecture will be delivered on June 5, at 5 p.m. in the Lecture Theatre at the University Museum by Dr. J. S. Plaskett, director of the Dominion Astrophysical Observatory, Victoria, B.C., Canada, who will take as his subject: "Dimensions and structure of the Galaxy."

Mr. J. N. L. Baker has been appointed University reader in historical geography for seven years from October 1. Miss B. M. Blackwood has been 